\title{
Das proposiçóes da política às práticas dos serviços: há novidades nos Centros de Atenção Psicossocial Álcool e Drogas?
}

\section{| ${ }^{1}$ Ana Regina Machado, ${ }^{2}$ Celina Maria Modena, ${ }^{3}$ Zélia Maria Profeta da Luz |}

Resumo: Os Centros de Atenção Psicossocial Álcool e Drogas (Caps AD) ofertam atenção no Sistema Único de Saúde às pessoas com problemas decorrentes do uso de drogas, a partir de inovaçóes associadas à inclusão da atenção psicossocial e da redução de danos em sua concepção de atenção. Buscando compreender como têm sido desenvolvidas as práticas desses serviços, bem como a lógica de atenção que adotam, realizamos uma pesquisa, de abordagem qualitativa, que envolveu observação participante, entrevistas semiestruturadas com gerentes e grupos focais com usuários, familiares e trabalhadores em três Caps AD, localizados no município de Belo Horizonte-MG. Constatamos que estes serviços priorizam práticas que produzem acolhimento, vínculos sociais e atenção aos comprometimentos de saúde. Adotam a redução de danos, a atenção psicossocial e o cuidado como lógica de atenção. Realizam a atenção em serviços abertos, porém com pouca articulação com os recursos comunitários e territoriais. A pesquisa permitiu compreender que os Caps AD realizam práticas coerentes com as inovaçôes propostas, que buscam ampliar as possibilidades de vida das pessoas que usam drogas.

> Palavras-chave: assistência integral à saúde; centros de tratamento de abuso de substâncias; usuários de drogas.

\author{
1 Instituto René Rachou, \\ Fundação Oswaldo Cruz. \\ Belo Horizonte-MG, Brasil \\ (anarmachado@uol.com.br). \\ ORCID: 0000-0001-8614-2533 \\ 2 Instituto René Rachou, \\ Fundação Oswaldo Cruz. Belo \\ Horizonte-MG, Brasil (celina. \\ modena@fiocruz.br). \\ ORCID: 0000-0001-5035-3427 \\ ${ }^{3}$ Instituto René Rachou, \\ Fundação Oswaldo Cruz. Belo \\ Horizonte-MG, Brasil (zelia. \\ profeta@fiocruz.br). \\ ORCID: 0000-0002-0819-3025
}

Recebido em: 09/05/2019 Aprovado em: 15/07/2019 Revisado em: 17/02/2020 


\section{Introdução}

Os Centros de Atenção Psicossocial Álcool e outras Drogas (Caps AD) foram criados para ofertar no Sistema Único de Saúde (SUS) atenção às pessoas com problemas decorrentes do uso de álcool e outras drogas. Tais serviços deveriam desenvolver práticas capazes de produzir inovaçôes em relação aos tratamentos já existentes, muitas vezes restritos às abordagens médico-psiquiátricas ou religiosas e às internaçóes em hospitais psiquiátricos ou em comunidades terapêuticas, que adotavam a abstinência como condição e meta exclusiva da atençáo. A Portaria no 336/2002 e a Política do Ministério da Saúde para Atenção Integral aos Usuários de Álcool e outras Drogas (2003) apresentaram as primeiras definiçóes sobre a atenção em Caps AD (BRASIL, 2002, 2003). Os serviços, para manter coerência com os princípios do SUS (universalidade, integralidade e igualdade), deveriam assegurar acesso às açóes de saúde de acordo com as necessidades das pessoas que usam drogas. Os Caps $\mathrm{AD}$ deveriam também, para manter coerência com a política de saúde mental formulada a partir da Reforma Psiquiátrica, constituirse como serviços abertos e territorializados e ofertar atenção às pessoas que usam drogas considerando seus processos de sofrimento e adoecimento e promovendo cidadania e autonomia (BRASIL, 2003). O Ministério da Saúde (MS) propôs ainda que os Caps $\mathrm{AD}$ adotassem a concepção ampliada de redução de danos, buscando contribuir para o acolhimento, o cuidado, a construção de vínculos sociais, a cidadania, a autonomia, o protagonismo dos usuários e a redução de riscos e danos associados ao uso de drogas, sem exigir a abstinência como condição ou meta exclusiva de suas práticas (BRASIL, 2003).

Considerando esta multiplicidade de finalidades, os Caps AD deveriam ofertar uma atenção em rede que envolvesse pontos de atenção do SUS e de outros setores, além de recursos do território. Em 2011, o MS propôs a criação da Rede de Atenção Psicossocial (RAPS) e definiu os serviços do SUS que deveriam se comprometer com a atenção às pessoas com necessidades decorrentes do uso de drogas (BRASIL, 2011). Com a criação da RAPS, as atribuiçôes do Caps AD foram definidas mais uma vez. Os serviços deveriam, então, constituir-se como referência de cuidado e proteção para usuários e familiares em situações de crise e de maior gravidade; acolher usuários sem qualquer barreira de acesso; construir, de maneira compartilhada com usuários, projetos terapêuticos singulares 
que considerassem o contexto social e as possibilidades de ampliaçáo da vida; contribuir para a reabilitação psicossocial; definir profissionais de referência para os usuários; ofertar práticas de acordo com as necessidades; ofertar cuidado em situaçôes de comorbidade psiquiátrica ou clínica; e realizar atendimentos de casos compartilhados com outros pontos de atenção (BRASIL, 2012). Os Caps AD deveriam, portanto, constituir-se como um campo de práticas comprometido com a produção de saúde e de vida das pessoas que usam drogas.

Entre os anos 2002 e 2014, foram implantados 378 Caps AD no Brasil (BRASIL, 2015). O desenvolvimento da atenção nestes serviços, a partir das inovaçôes propostas pelo MS, tem se constituído como desafio em um contexto histórico e social marcado pela criminalização das pessoas usuárias de drogas, no qual as práticas de saúde têm sido desenvolvidas como parte de um projeto global de guerras às drogas, que busca reforçar a lógica de controle das condutas desse segmento da população (SOUZA, 2018). Os Caps AD, que em sua concepçáo deveriam produzir rupturas com essa lógica, têm desenvolvido suas práticas em meio a muitas disputas.

Nesse contexto, torna-se importante compreender quais possibilidades de atenção têm sido sustentadas nos Caps AD. Pesquisas realizadas mostram que alguns serviços têm adotado modos de atenção coerentes com as proposiçôes do MS que envolvem: a produção de acolhimento e cuidado (FODRA; COSTA-ROSA, 2009; MOURA; SANTOS, 2011; MARQUES; MANGIA, 2013; LACERDA; FUENTES-ROJAS, 2017); a promoção de cidadania e de inclusão social (LACERDA; FUENTESROJAS, 2017); a disponibilização de medicamentos (MORAES, 2008); a produção de novas formas de gestão do consumo de drogas (MOURA; SANTOS, 2011); a oferta de cuidado ao corpo e a proteçáo temporária (MARQUES; MANGIA, 2013). As pesquisas mostram, por outro lado, que alguns Caps $\mathrm{AD}$ ofertam uma atenção que se distancia daquilo que deveriam ofertar. Os serviços apresentam dificuldades no acolhimento, muitas vezes restrito às pessoas abstinentes e feito por trabalhadores pouco disponíveis (MORAES, 2008; FODRA; COSTA-ROSA, 2009; MOURA; SANTOS, 2011; LACERDA; FUENTES-ROJAS, 2017); dificuldades na promoção de inclusão social e de articulação de redes (MORAES, 2008; FODRA; COSTAROSA, 2009); dificuldades na promoção de autonomia (WANDEKOKEN; QUINTANILHA; DALBELLO-ARAÚJO, 2015; LACERDA; FUENTESROJAS, 2017); dificuldades de reconhecimento dos usuários como sujeitos e cidadãos 
(MORAES, 2008); predomínio de práticas biomédicas (FODRA; COSTA-ROSA, 2009; VASCONCELOS; PAIVA; VECCHIA, 2018); adoção da compreensão individualista e descontextualizada dos problemas associados ao consumo de drogas (VASCONCELOS; PAIVA; VECCHIA, 2018); adoção de lógica disciplinar e punitiva (WANDEKOKEN; QUINTANILHA, DALBELLO-ARAÚJO, 2015). As pesquisas permitem compreender que os Caps $\mathrm{AD}$ desenvolvem diferentes práticas e adotam lógicas de atenção contraditórias, às vezes coerentes com o modo de atençấo proposto pelo MS, às vezes coerentes com o controle das pessoas que usam drogas que a política de guerra às drogas busca realizar.

Buscando ampliar as compreensões sobre o modo de atenção dos Caps $\mathrm{AD}$, as práticas que produzem e as lógicas que adotam, realizamos uma pesquisa qualitativa nos três serviços do município de Belo Horizonte-MG. Compreendemos que esta pesquisa, assim como outras produçóes de conhecimento sobre as práticas de serviços de base territorial e comunitária de atenção em álcool e outras drogas, tem relevância para uma rede que conta com quase 400 Caps $\mathrm{AD}$ e com outros serviços que compartilham a tarefa de ofertar atenção no SUS às pessoas que usam drogas. Compreendemos também que o estudo das práticas, do que tem sido possível produzir no cotidiano dos serviços a partir dos encontros entre usuários, trabalhadores, familiares e gerentes, é um meio privilegiado para analisar as contribuiçôes de uma política e do modo de atenção que propóe.

\section{Metdologia}

No desenvolvimento da pesquisa, de abordagem qualitativa, buscamos produzir interpretaçóes sobre as práticas de atenção desenvolvidas em Caps $\mathrm{AD}$ considerando duas proposiçôes de Santos (2007): alargar o presente de maneira a evitar o desperdício das experiências que nele emergem e adotar referenciais teóricos produzidos nos próprios países que as desenvolvem para compreendê-las (SANTOS, 2007).

Para nos aproximar das experiências que os Caps $\mathrm{AD}$ desenvolvem, realizamos um percurso metodológico que envolveu diferentes técnicas e a participação de diferentes sujeitos dos três Caps AD do município de Belo Horizonte. No trabalho de campo, desenvolvido entre outubro de 2016 e setembro de 2017, realizamos um total de três entrevistas semiestruturadas com gerentes (3 participantes), três grupos focais com usuários (30 participantes), três grupos focais com familiares (20 participantes), três 
grupos focais com trabalhadores de nível médio e superior (31 participantes), além de 120 horas de observação participante nas diferentes atividades dos Caps AD (plantôes, permanência-dia, oficinas, assembleias, grupos de familiares, atividades no território e reuniōes de equipe).

A análise e a interpretação dos dados seguiram as etapas propostas por Gomes et al. (2005). Após realizar várias leituras do material produzido no trabalho de campo (transcriçôes de entrevistas e grupos focais e registros do diário de campo), criamos uma estrutura de análise que permitiu a organização do material por grupo de sujeitos participantes e, posteriormente, por categorias empíricas (acolhimento e vínculo, atenção aos comprometimentos orgânicos e psíquicos, promoção de cidadania). Desta forma, foi possível não só identificar proximidades e divergências nas interpretaçôes dos diferentes sujeitos, bem como a triangulação das interpretaçóes obtidas por meio das diferentes técnicas. Após análise, realizamos a interpretação dos dados, utilizando a produção teórica do campo da Saúde Coletiva sobre atenção em saúde, do campo de álcool e outras drogas sobre a atenção em serviços de saúde e do campo da Saúde Mental sobre as práticas em serviços abertos e comunitários. Na produção da interpretação, buscamos considerar também os processos sociais e históricos (criminalização e patologização do uso de drogas, exclusão e desqualificação social) que conformam as práticas de saúde e as vidas das pessoas que usam drogas no Brasil. Desta forma, aproximamo-nos não só da proposição de Santos (2007) de compreender os objetos investigados a partir da produção teórica de autores que se encontram mais próximos a eles, mas também da Hermenêutica-Dialética. De acordo com Minayo (2014), este referencial teórico-metodológico contribui para a tarefa de compreender e criticar o objeto, de identificar os consensos e dissensos, de considerar a cotidianidade e os macroprocessos, as contradiçôes e os acordos.

Os dados utilizados neste artigo fazem parte da pesquisa, realizada durante o curso de doutorado, intitulada "Atenção às pessoas dependentes ou em uso prejudicial de álcool e outras drogas: uma análise dos cuidados nos Caps AD de Belo Horizonte-MG.” (CAE n.57956416.0.0000.5091). A realização da pesquisa não envolveu conflitos de interesse, seguiu todas as exigências previstas Resolução 466/ 2012 do Conselho Nacional de Saúde e foi aprovada pelos Comitês de Ética em Pesquisa do Instituto René Rachou da Fundação Oswaldo Cruz e da Secretaria Municipal de Saúde de Belo Horizonte. 


\section{Resultados e Discussão}

Os resultados permitiram compreender que os Caps AD de Belo Horizonte priorizam o desenvolvimento de práticas de produção de acolhimento e vínculos e de atenção aos comprometimentos de saúde das pessoas que usam drogas. Ofertam também, ainda que sem priorização, práticas que contribuem para a produção de cidadania. Incluem elementos da redução de danos, da atenção psicossocial e do cuidado em suas lógicas de atenção. Sustentam a atenção em serviços abertos, porém com pouca articulação com os recursos comunitários e territoriais.

A partir das categorias empíricas (acolhimento e vínculo, atenção aos comprometimentos orgânicos e psíquicos, promoção de cidadania), buscamos destacar as interpretaçóes dos sujeitos participantes sobre a atenção nos Caps AD, bem como o modo como essa atenção tem sido cotidianamente produzida. Buscamos, ao fim, destacar as aproximaçóes e os distanciamentos entre a atenção produzida nos Caps AD e aquela proposta pelo Ministério da Saúde em suas políticas e normativas.

\section{As práticas produzidas nos serviços Acolbimento, cuidado e vínculo}

Usuários, familiares, trabalhadores e gerentes afirmaram, de maneira consensual, que os Caps AD privilegiam o desenvolvimento de práticas que produzem relaçôes interpessoais: "acolhimento", "atenção", "reconhecimento do outro como ser humano", "vínculos", “convivência”, “apoio” e "cuidado”. Tal resultado foi também encontrado em outras pesquisas realizadas em Caps AD (FODRA; COSTA-ROSA, 2009; MOURA; SANTOS, 2011; MARQUES; MANGIA, 2013; LACERDA; FUENTES-ROJAS, 2017).

Os sujeitos participantes afirmaram, nos grupos focais, que os Caps AD acolhem as pessoas que fazem uso de drogas como seres humanos, sem privilegiar aspectos patológicos ou estigmas que podem ser associados a seus modos de vida. Os participantes afirmaram:

As pessoas aqui são tratadas como seres humanos. Este diferencial saltou aos meus olhos quando cheguei aqui. Os usuários também comentam que aqui são tratados como seres humanos, não como viciados. (Trabalhadora 4, grupo focal, Caps AD1).

Eu sou muito bem atendido. As pessoas que trabalham aqui dão muita atenção pra gente e essa atenção tá mudando meu pensamento. Lá fora olham você com outros olhos, é mais difícil. (Usuário 5, grupo focal, AD2). 
O reconhecimento da condição humana e da condição de sujeito parece não fazer parte do cotidiano da vida das pessoas atendidas nos Caps AD, que, muitas vezes, se reconhecem e são reconhecidas como objetos. As dificuldades que têm para regular o uso de drogas e as marcas de diferentes processos sociais - criminalização, estigmatização, exclusão, desclassificação social - na produção de suas subjetividades contribuem para isso. Os diferentes sujeitos participantes reconheceram a presença desses processos sociais nas vidas dos usuários dos Caps AD:

O meu filho não tem um amigo. Ninguém! Só tinha um cachorrinho lá em casa que gostava dele, o resto só quer matar ele. Porque ele usa drogas ele é o pior da rua, ele é o ladrão, ele é tudo de ruim. Tudo que aparece de errado foi ele que fez. As pessoas tomam raiva tanto do vício como dele e aí ele mergulha mais ainda. Ninguém gosta dele só porque ele usa drogas. (Familiar 9, grupo focal, Caps AD3).

Eu fui expulsa de casa, lá ninguém quer saber de mim, eu tô morando num abrigo. (Usuária 3, grupo focal, Caps AD1).

São pessoas que estão à margem da margem e são tratadas como objetos, muitas vezes se resumem a essas substâncias que elas fazem uso. (Trabalhadora 1, grupo focal, Caps AD2).

Tem muito preconceito, muito estigma, é uma população que sempre foi marginalizada. (Gerente, entrevista semiestruturada, Caps AD1).

Alguns autores contribuem para compreender como esses processos sociais dificultam o reconhecimento das pessoas que usam drogas como seres humanos e como sujeitos. Souza (2016) observa que a desclassificação social gera sentimentos de ser "menos que humanos" às pessoas que usam crack e vivem nas ruas. Souza (2018) observa que a criminalização e a patologização do uso de drogas produzem subjetividades marcadas pela delinquência e pela doença, o que gera dificuldades e ambiguidades no campo das relaçóes sociais, inclusive entre usuários e trabalhadores de saúde (SOUZA, 2018). Ayres (2011), ainda que sem se referir especificamente às pessoas que usam drogas, afirma que processos de vulnerabilização, que produzem o "não reconhecimento" ou o desrespeito, têm consequências danosas para os sujeitos e expressam fragilidades éticas e políticas sobre as quais se assentam as relaçóes sociais (AYRES, 2011). A esses processos, ainda segundo o autor, podem se associar déficits de saúde, de cidadania, de inclusão e de reconhecimento que justificam a necessidade do cuidado nas práticas de saúde. Nestas práticas, estão presentes, além de uma dimensão tecnológica (aplicação de saberes sob a forma de tecnologias), uma dimensão prática (consideração de aspectos existenciais, éticos e políticos) que implica o reconhecimento do outro como sujeito e a valorização 
da construção de relaçôes intersubjetivas no espaço assistencial (AYRES, 2011). Ayres (2000) utiliza o conceito de cuidado para designar essa dimensão prática que valoriza "[...] a intersubjetividade viva no momento assistencial [que] permite escapar a uma objetivação "dessubjetivadora" exatamente porque ali se efetiva uma troca, um espaço relacional, que extrapola o tecnológico" (AYRES, 2000, p. 119). Nos Caps $\mathrm{AD}$ pesquisados, o acolhimento e a produção de vínculos contribuem para assegurar a presença do cuidado nas práticas dos serviços, conforme destacado pelos diferentes sujeitos participantes:

A oferta da acolhida, do acolhimento é primordial às outras, porque aí você cria vínculo. (Gerente, entrevista semiestruturada, Caps AD2).

As pessoas aqui são muito carinhosas, recebem a gente, assim, sem nenhum tipo de preconceito, sem nenhum tipo de restrição. (Familiar 7, grupo focal, Caps AD2).

A atenção dos profissionais foi muito importante pra mim, pro tratamento do meu filho, porque aqui ele criou um vínculo. Ele estava na rua, foi uma situação muito sofrida pra gente. Aqui ele criou um vínculo, ele gosta de vir, ele pede pra vir. (Familiar 2, grupo focal, Caps AD1).

Aqui os profissionais são muito próximos do paciente, né, em relação ao que o paciente tá sentindo, tá passando... O acolhimento é muito bom, ajuda muito na redução da droga. (Usuário 5, grupo focal, Caps AD3).

Apesar do consenso constatado nos grupos focais e nas entrevistas sobre a importância das práticas produtoras de relaçôes intersubjetivas, na observação participante percebemos que os três Caps $\mathrm{AD}$ não as sustentam da mesma forma.

Em dois serviços pesquisados, foi possível observar a coexistência dessas práticas com outras que reproduzem relaçôes sociais objetivadoras, vivenciadas pelos usuários em seus diferentes contextos de vida. No Caps AD1, nas oficinas, nos plantóes, na sala de espera e nas atividades no território, observarmos trabalhadores disponíveis para o acolhimento e para o cuidado, sem realizar julgamentos ou exigências junto aos usuários. Na Permanência-Dia (PD), entretanto, presenciamos relaçóes sociais baseadas na disciplina e no controle ou mesmo a ausência de cuidados: usuários ociosos ou adormecidos pelos corredores, técnicos de enfermagem exercendo funçôes de vigilância, pouca convivência entre técnicos de nível superior e usuários. No Diário de Campo, um registro ilustra esta situação:

$\mathrm{Na} \mathrm{PD}$, muitos usuários estavam dormindo, alguns jogavam baralho, um grupo tocava violâo, um grupo parecia entediado... Nenhum técnico de nível superior presente. Pergunto-me pelo significado da PD para a equipe e para os usuários, ela parece não marcar 
um antes e um depois, um dentro e um fora, uma descontinuidade ou diferença na vida dos usuários. (Pesquisadora, Diário de Campo, outubro de 2016).

No Caps AD 2, foi possível observar momentos de acolhimento e de cuidado nos grupos, oficinas e assembleias. Alguns acontecimentos, entretanto, sinalizavam dificuldades de encontro e convivência entre trabalhadores e usuários: reuniôes de passagens de plantão muito extensas com quase duas horas de duração (tempo em que a equipe deixava de estar com os usuários), usuários dispersos pelo serviço sem muitos vínculos com outros usuários ou com os trabalhadores, usuários ociosos pedindo insistentemente para sair da PD.

Os grupos focais realizados com usuários nos dois serviços corroboraram estas observaçóes. Usuários queixaram-se da ociosidade na $\mathrm{PD}$ e da dificuldade para conversar com os técnicos de referências ou médicos. O cuidado está presente, mas também ausente das práticas dos dois serviços. Em alguns momentos, estes serviços não sustentam uma distinção capaz de justificar o interesse ou mesmo a presença dos usuários. Eles poderiam estar nos Caps AD, como em outros lugares.

No Caps $\mathrm{AD} 3$, observamos uma proximidade maior entre trabalhadores e usuários. Trabalhadores da área administrativa participavam das atividades da PD, gerente, técnicos de referência e médicos coordenavam oficinas, um redutor de danos articulava as atividades no território e junto com os técnicos de enfermagem apoiavam os usuários em suas necessidades e demandas cotidianas. Mais do que ocupação, as atividades da PD proporcionavam o encontro e o convívio entre usuários e trabalhadores, para além daqueles previstos nas áreas profissionais e isso parecia fazer a diferença. Lobosque (2003) e Almeida (2018) afirmam a importância de os trabalhadores estarem ao lado dos usuários, tanto como técnicos quanto como sujeitos, dispostos a conviver e a inventar motivos e sentidos para permanecerem juntos em serviços abertos, como os Caps, mas também fora deles. As relações intersubjetivas construídas parecem ter contribuído para que o Caps AD 3 se constituísse como um "contraespaço", como propóe Parada (2003), capaz de se diferenciar dos outros espaços pelos quais os usuários circulavam. Parada (2003), a partir das contribuiçôes de Foucault, afirma que as instituiçôes devem produzir heterotopias, ou seja, espaços que se diferenciam de outros, se pretenderem oferecer acolhimento às pessoas que usam drogas. O autor afirma que o "[...] drama de vários de nossos pacientes é justamente chegar a um ponto em que os lugares não se distinguem em quase nada 
e se sucedem em repetição monótona e mortífera" (PARADA, 2003, p.226). Os serviços de atenção devem, então, se constituir como lugares distintos, capazes de produzir sentidos às pessoas que usam drogas e que permitam a elas encontrar “... o que tiveram dificuldade de encontrar em outro lugar" (PARADA, 2003, p.226). As concepçôes e posturas da equipe e a organização da atenção de modo a favorecer encontros e convivências produzem distinçôes entre o dentro e o fora do Caps AD 3. O serviço é reconhecido como espaço de acolhimento e cuidado e também como espaço terapêutico, onde é possível construir novas formas de gestão do uso de drogas, coincidentes ou não com a abstinência (CECÍLIO, 2018). No grupo focal do Caps AD3, os usuários afirmaram que:

O serviço contribuiu pra me dar essa livre escolha de usar ou não usar drogas. (Usuário 3 , grupo focal, AD3).

Eu não espero ser curado $100 \%$ mas eu queria sair daqui e voltar a ter a minha vida (Usuário 5, grupo focal, Caps AD3).

Tem três meses que eu tô aqui e não uso crack, eu tô liberto. O serviço contribuiu muito pra minha recuperação. Isso valeu pra mim. A fissura acabou. (Usuário 7, grupo focal, AD3).

O Caps AD3 se constitui como espaço de acolhimento, de cuidado e de convivência. Dessa maneira, parece viabilizar-se também como espaço terapêutico.

\section{Atenção aos comprometimentos orgânicos e psíquicos}

Nos grupos focais, os sujeitos participantes ressaltaram também a oferta de práticas de atenção aos comprometimentos orgânicos e psíquicos nos Caps AD. Usuários e familiares destacaram a importância da disponibilização e utilização de medicamentos e dos atendimentos dos médicos e dos técnicos de referência na atenção que recebem nos serviços. Gerentes e trabalhadores destacaram, além da importância desses atendimentos, a oferta de atenção às situaçôes de crises e às urgências. A observação participante confirmou a importância dessas práticas. Os usuários, com frequência, recebem atenção a diferentes comprometimentos, tais como: síndromes de abstinência, intoxicação, hipertensão, hepatites, Aids, agitação psicomotora, depressão, psicose e tentativas de autoextermínio. As equipes de plantão não apresentam dificuldades na oferta desta atenção. Quando necessário, acionam outros serviços como Unidades de Pronto Atendimento (UPA), Unidades Básicas de Saúde (UBS) ou serviços especializados. 
Os trabalhadores, com diferentes formaçóes, compartilham o atendimento às crises e também o acompanhamento dos usuários. Não observamos relaçôes desiguais de poder entre os trabalhadores de nível superior, nem o predomínio de uma abordagem biomédica nos Caps AD. Resultado que se diferencia daqueles encontrados por Fodra e Costa-Rosa (2009) e Vasconcelos, Paiva e Vechhia (2018), que constataram o predomínio de práticas medicamentosas ou do modelo biomédico nesses serviços. A adoção de uma concepção ampliada sobre a atenção, a postura dos trabalhadores e gerentes e mesmo o reconhecimento da complexidade das situaçóes de crise, que envolvem comprometimentos orgânicos e psíquicos e também vulnerabilidades sociais, relativizam o lugar do saber e do poder biomédico. Uma situação registrada no Diário de Campo contribui para a compreensão da complexidade de crises que se apresentam nos serviços e como a equipe se organiza para atendê-la:

Uma usuária de cocaína e de álcool com 68 anos de idade foi levada pela polícia ao plantão da manhã. Havia quebrado móveis e agredido fisicamente alguns familiares em sua casa. A equipe a acolheu e a incluiu no leito de desintoxicação. Assim que teve oportunidade, a usuária saiu do serviço. No plantão da tarde, a família fez vários contatos e pediu ajuda. A usuária estava muito agitada e a família a havia contido. O Serviço de Atendimento Móvel de Urgência (SAMU) e a Polícia Militar (PM) estavam se recusando a atendê-la. Os técnicos de plantão conversaram várias vezes com os familiares por telefone e orientaram a insistir com o SAMU para levar a usuária ao Caps AD. No fim da tarde, o SAMU leva a usuária ao serviço, que é imediatamente atendida pela equipe e acolhida no leito mais uma vez. O médico a atende e manifesta sua preocupação. Pergunta pelo sentido de medicar uma mulher que usa cocaína há mais de 50 anos e que não quer ficar no serviço. Um técnico de plantáo afirma que ela precisa ficar e que o Caps AD tem condiçôes de acolhê-la, diz que a medicaçáo pode ajudar e que as técnicas de enfermagem da Hospitalidade Noturna (HN) podem acionar o Serviço de Urgência Psiquiátrica (SUP) durante a noite, se necessário. $\mathrm{O}$ médico parece não perceber muito sentido, mas acaba medicando a usuária. No início da noite, a usuária começa a gritar, não quer ficar no leito, começa a agredir o filho. Logo depois, tranquiliza. O medicamento começa a fazer efeito. A usuária pernoita no serviço. (Pesquisadora, Diário de Campo, novembro de 2016).

A complexidade desta situação - que envolveu aspectos relacionais, agitaçôes e agressóes, a recusa da usuária a ser medicada e a permanecer no serviço e a mobilização de várias instituiçôes, como a PM, o SAMU e a família — demonstra a importância dos diferentes saberes e profissionais para manejá-la. Os técnicos plantonistas sustentaram a possibilidade de acolhimento da usuária no Caps $\mathrm{AD} 1$, quando a família não sabia mais o que fazer, e o SAMU parecia não apostar na possibilidade de atendimento à usuária. A atuação e a prescrição do médico contribuíram para 
que a usuária suportasse permanecer no serviço. Além dos saberes profissionais, o atendimento a essa situação envolveu também uma lógica de atenção construída a partir da redução de danos (que permitiu ofertar o cuidado possível para assegurar a sobrevivência da usuária de maneira menos danosa), da atenção psicossocial (que permitiu compreender a complexidade psicossocial da crise, bem como sustentar a possibilidade de atendê-la em um serviço aberto e territorial) e também do cuidado (que favoreceu a oferta de acolhimento, escuta e apoio).

Nos Caps AD pesquisados, todos os usuários são atendidos por técnicos de referência que podem ter diferentes formaçôes profissionais: terapia ocupacional, serviço social, enfermagem ou psicologia. Estes técnicos têm como função realizar acompanhamentos mais próximos dos usuários, a partir da escuta singularizada de seus sofrimentos. Alguns usuários reconhecem a importância desses técnicos: são "mais profissionais", "mais estudados", mais capazes de ajudá-los a "suportar a fissura" e a construir "novos projetos de vida”. Outros usuários, entretanto, não fazem distinção entre os técnicos de referência e os outros trabalhadores dos Caps AD.

Durante a observação participante, mais do que nos grupos focais, foi possível perceber que parte importante da atenção realizada nos Caps AD se destina ao atendimento aos comprometimentos de saúde dos usuários, em situaçôes de crise ou não.

\section{Promoçâo de cidadania}

Nos Caps AD pesquisados, algumas práticas são realizadas de maneira a favorecer o acesso a direitos sociais básicos. Os usuários reconhecem a importância dessas práticas:

Tudo que eu preciso eu consigo aqui, os remédios e a alimentação, o café da manhã, o almoço e o café da tarde. (Usuário 5, grupo focal, Caps AD2).

Aqui é como se fosse a minha casa, eu não tenho casa, sou morador de rua. Eu venho aqui 3 vezes por semana... Tomo meu banho, me alimento. (Usuário 1, grupo focal, Caps AD3).

As gerentes dos serviços consideram que essas práticas são importantes para os usuários e que cabe aos Caps AD ofertá-las. Entre os trabalhadores, não há consenso. Alguns consideram que os Caps AD podem se tornar assistencialistas e deixarem de ser terapêuticos, se ofertarem essas práticas. Outros compreendem que não é possível cuidar sem que direitos básicos de sobrevivência sejam assegurados aos usuários, não só pelos Caps $\mathrm{AD}$, mas também por outros serviços e redes de apoio. Campos (2006) propóe que os serviços de saúde considerem os sujeitos, seus contextos de vida e seus 
sofrimentos e adoecimentos na oferta de suas práticas. Desconsiderar qualquer um destes elementos e também as necessidades que deles decorrem pode contribuir para deixar fora dos serviços de saúde as pessoas que deles necessitam. Compreendemos que práticas que buscam contribuir para a promoção de direitos sociais básicos não são de responsabilidade exclusiva dos Caps $\mathrm{AD}$ mas, tampouco, devem ser estranhas a eles.

Os Caps AD contribuem para assegurar o direito ao acesso a diferentes serviços de saúde, de acordo com as necessidades dos usuários. Ainda que o SUS tenha como princípios a universalidade e a integralidade e devesse assegurar esse direito a todos, processos de estigmatização, de exclusão e de desqualificação social de pessoas que usam drogas dificultam o acesso a serviços de saúde. Uma das gerentes afirmou:

Muitos usuários, mesmo estando ali, na praça, que é do lado do Centro de Saúde, não entram lá... Eles entram na UPA, porque entram levados. Mas eles não se sentem acolhidos, convidados, pertencentes àquele lugar. (Gerente, entrevista semiestruturada, Caps AD2).

Os usuários afirmaram a contribuição dos Caps $\mathrm{AD}$ na promoção do acesso aos serviços de saúde de que necessitam:

Se você precisar de alguma coisa de um médico, de um profissional fora daqui, os profissionais daqui te encaminham. As pessoas que chegam aqui, elas podem estar drogadas e ter um problema muito mais sério, um problema no fígado, por exemplo, igual eu tive né? Foi através deste serviço que eu pude saber. (Usuário 1, grupo focal, Caps AD2).

Eu tava com o pé inchado, tropecei num toco de madeira e aí inflamou. Aí eles me encaminharam lá pra UPA. Se a gente sentir mal, a gente vai pra UPA e eles atendem na hora. (Usuário 1, grupo focal, Caps AD1).

Outras práticas, como a circulação por diferentes espaços da cidade (exposiçóes, cinema, centro da cidade e parques), a retirada de documentos e a inserção dos usuários em cursos profissionalizantes, que buscam contribuir para a promoção de cidadania, reinserção e reabilitação psicossocial, são realizadas nos Caps AD. Alguns sujeitos participantes afirmaram a importância de compreender melhor as contribuiçôes dessas práticas para os usuários e de ofertá-las com mais frequência.

Os passeios, a dimensão das artes e as oficinas trazem algo que a gente ainda não consegue captar. Um paciente que tem dificuldade de andar de metrô sozinho, aí você possibilita isso a ele, com ele. Outro que nunca tinha ido ao cinema e aí ele vivencia isso com a gente. As oficinas e os passeios trazem muitas oportunidades, a gente consegue produzir saúde por outro viés. (Trabalhadora 7, grupo focal, Caps AD1).

Eu sonho com um Caps $\mathrm{AD}$ que tenha vários espaços com atividades simultâneas. Mas eu não sei se tem que ser tudo dentro do Caps $\mathrm{AD}$, né? Talvez fomentar mais açôes no território, fora daqui. (Gerente, entrevista semiestruturada, Caps AD3). 
Os Caps $\mathrm{AD}$ contribuem, mas poderiam contribuir mais, para que os usuários possam encontrar pertencimento nos diferentes espaços sociais. Fazer caber pessoas que apresentam diferenças, não só nos serviços de saúde mas em todo campo social, é um dos princípios das práticas antimanicomiais de Saúde Mental, implantadas no Brasil desde o início dos anos 90 (LOBOSQUE, 1997; SILVA, 2015). Adotar tal princípio cotidianamente no desenvolvimento das práticas ainda é um desafio para os Caps $\mathrm{AD}$. $\mathrm{Na}$ observação participante foi possível perceber que, embora valorizadas por gerentes e por parte dos trabalhadores, as atividades relacionadas à promoção de cidadania, que exigiriam forte articulação com o território e com outras redes, não ocupam lugar central nas práticas dos Caps AD.

Apesar das dificuldades de articular redes, os serviços têm possibilitado que as pessoas mantenham os vínculos no território enquanto se tratam. O cuidado em liberdade, proposto pelo movimento antimanicomial e incorporado ao modo de atenção psicossocial proposto pelo MS, foi reconhecido como um importante diferencial dos Caps AD pelos usuários e seus familiares. Tal resultado contraria uma crítica corrente no campo social de que a expectativa de usuários e familiares restringese a tratamentos baseados na internação. De acordo com usuários e familiares:

Quando eles ficam presos — não é preso, é em tratamento fechado, mas eles se sentem presos - eles acham assim que a família excluiu eles da vida, que jogou eles pra lá. (Familiar 3, grupo focal, AD3).

Eu gostei muito de ter meu marido por perto enquanto ele se tratava, mesmo com a dificuldade toda que eu passei com ele. Eu acho que se ele tivesse sido internado, ele estaria revoltado com a família. (Familiar 1 grupo focal, AD2).

Não é aquele lugar que você fica preso, não é obrigatório, né? Porque eu quero o meu tratamento, mas também quero a retomada de vida social, né? (Usuário 7, grupo focal, Caps AD2).

Esse negócio de ficar fechado não dá, já passei por três comunidades terapêuticas, mas eu sou livre, eu prezo demais minha liberdade, onde meu nariz aponta eu tô indo. (Usuário 1, Grupo focal, Caps AD3).

Participar da construção de arranjos de vida no território que podem favorecer a ampliação da autonomia dos usuários é uma das tarefas dos Caps AD. Considerada como finalidade das açóes de saúde por autores do campo da Saúde Coletiva, da Atenção Psicossocial e da Redução de Danos, a autonomia pode ser compreendida como a capacidade de cada sujeito de compreender e de atuar sobre si e sobre o mundo (CAMPOS; AMARAL, 2007). Para Onocko-Campos e Campos (2006), 
a autonomia não é produzida apenas individualmente, envolve uma coprodução de sujeitos, políticas públicas, instituiçôes e cultura (ONOCKO-CAMPOS; CAMPOS, 2006). Na observação participante, a ampliação da autonomia não se apresentou como uma diretriz das práticas dos Caps AD. As situaçóes apresentadas pelos usuários nos serviços revelam, sobretudo, limites para a sua promoção: alguns apresentam vínculos muito intensos com as drogas, muitos têm suas vidas marcadas por processos sociais e por políticas de controle. Sem desconhecer os limites e contradiçôes que envolvem a ampliação de autonomia no campo da atenção às pessoas que usam drogas, o Ministério da Saúde a incluiu no modo de atenção que os Caps AD deveriam sustentar. No cotidiano dos serviços pesquisados, entretanto, o fomento e a participação dos Caps $\mathrm{AD}$ na co-produção de autonomia das pessoas que usam drogas ainda se apresentam como desafios.

Manter a promoção de cidadania e a ampliação da autonomia como desafios cotidianos dos Caps AD e ampliar as compreensôes sobre estes processos e suas contradiçóes podem contribuir para evitar que os serviços, como temem alguns trabalhadores, se tornem assistencialistas. Podem também contribuir para favorecer o desenvolvimento de práticas atentas às múltiplas necessidades e direitos das pessoas que usam drogas e a ampliaçấo de suas possibilidades de vida, mesmo em condiçōes adversas.

\section{As práticas produzidas nos serviços e a política do Ministério da Saúde}

Os Caps $\mathrm{AD}$ pesquisados realizam práticas coerentes com o modo de atenção proposto pelo MS, entre os anos 2002 e 2015. Entre os diferentes aspectos observados nos serviços e considerados por trabalhadores, gerentes, usuários e familiares que permitem identificar essa coerência, destacamos: o reconhecimento das pessoas que usam drogas como sujeitos; a produção de acolhimento, cuidado e vínculos; a adoção da reduçáo de danos, da atençáo psicossocial e do cuidado na lógica de atenção; a promoção de acesso a direitos sociais básicos e a serviços de saúde; a sustentação do cuidado em liberdade, a permanência no território e a preservação dos laços sociais; a atenção aos comprometimentos orgânicos e psicossociais, em situaçóes de crise ou não; o acompanhamento dos usuários por técnicos de referência; a oferta de escuta; o compartilhamento de saberes e práticas na atenção; a ampliação das possibilidades de vida das pessoas que usam drogas. Constatamos, entretanto, que alguns aspectos destacados pelos sujeitos participantes e observados nos serviços apontam para um 
distanciamento entre atenção feita nos Caps $\mathrm{AD}$ e aquela proposta pelo MS, dentre eles, destacamos: não priorização da promoçáo de cidadania e de autonomia; baixa articulação com redes e recursos do território; ausência de cuidado e a adoção da lógica repressiva em alguns momentos da atenção.

\section{Considerações finais}

As políticas do SUS para atenção às pessoas que usam drogas, propostas entre os anos 2002 e 2015, apresentaram inovaçóes associadas à inclusão da atenção psicossocial e da redução de danos na formulação de seus princípios e diretrizes. Tais políticas buscaram promover rupturas com modos de atenção que reduzem as experiências de uso de drogas a crimes ou a doenças e que se orientam pela abstinência como condição ou meta exclusiva das ações de saúde.

Desde o ano de 2002, essas políticas têm sido implantadas no SUS. A pesquisa que realizamos buscou ampliar as compreensôes sobre as práticas de atenção que delas decorreram. Analisamos o que tem sido possível transpor das políticas para as práticas dos Caps $\mathrm{AD}$, a partir da perspectiva dos gerentes, trabalhadores, usuários e familiares. Demonstramos as inovaçôes que as práticas dos Caps $\mathrm{AD}$ têm produzido no campo da atençáo às pessoas que usam drogas.

Nos Caps $\mathrm{AD}$ pesquisados, práticas que produzem acolhimento, vínculos sociais e atenção a comprometimentos de saúde e que adotam a redução de danos, a atenção psicossocial e o cuidado como lógicas de atenção têm sido priorizadas. Há, entretanto, diferenças na sustentação destas práticas em cada um dos serviços, conforme buscamos demonstrar, seja no atendimento de uma crise em suas dimensôes orgânicas e psicossociais, seja na priorização de atividades que favorecem a convivência e os vínculos entre trabalhadores e usuários. Aproximaçóes e diferenças podem também ser observadas entre as práticas dos Caps $\mathrm{AD}$ que pesquisamos e as práticas desenvolvidas por outros serviços, objetos das pesquisas apresentadas em nossa revisão de literatura. Os Caps $\mathrm{AD}$ de Belo Horizonte apresentam, assim como alguns dos Caps $\mathrm{AD}$ pesquisados, coerência com o modo de atenção proposto pelo MS. Os serviços que pesquisamos distanciam-se, entretanto, de outros Caps $\mathrm{AD}$ pesquisados que desconsideram a cidadania e a subjetividade das pessoas que usam drogas, privilegiam os saberes e fazeres biomédicos e adotam lógicas disciplinares e punitivas, que contradizem o modo de atenção proposto pelo MS. 
Estas aproximações e diferenças permitem compreender as práticas de atenção dos Caps AD como produçôes sociais, que apresentam singularidades que as políticas de atenção podem favorecer, mas não assegurar.

Percebemos, na realização da pesquisa, que os Caps $\mathrm{AD}$ apresentam desafios e contradiçôes em suas práticas, quando assumem o compromisso de ampliar possibilidades de vida das pessoas que usam drogas em contextos sociais, políticos e culturais que, muitas vezes, buscam reduzi-las. Ressaltamos que novas análises, decorrentes de pesquisas acadêmicas ou da sistematização de reflexôes produzidas nos próprios serviços, com a participação de usuários, familiares, gerentes e trabalhadores, são necessárias para compreender as possibilidades de contribuição de práticas orientadas por princípios da redução de danos e da atençâao psicossocial, para as pessoas que vivem em contextos adversos e usam drogas. ${ }^{1}$

\section{Referências}

ALMEIDA, A. L. de. Cuidados no território: As práticas das equipes de Centros de Referência em Saúde Mental - CERSAM de Belo Horizonte. 2018. 196f. Dissertação (Mestrado em Saúde Coletiva). Instituto de Pesquisas René Rachou. Fundação Oswaldo Cruz, Belo Horizonte, 2018. AYRES, J. R. C. M. Cuidado: tecnologia ou sabedoria prática. Interface (Botucatu), v. 4, n. 6, p. 117-120, fev. 2000.

AYRES, J. R. C. M. O cuidado e o espaço público da saúde: virtude, vontade e reconhecimento na construção da política da integralidade. In: PINHEIRO, R.; SILVA JÚNIOR, A. G. (Orgs.). Cidadania no Cuidado: O universal e o comum na integralidade das açôes de saúde. Rio de Janeiro: CEPESC-IMS/UERJ-ABRASCO, 2011. p. 27-44.

BRASIL. Ministério da Saúde. Portaria GM MS no 336, de 19 de fevereiro de 2002. Brasília: Ministério da Saúde, 2002.

BRASIL. Ministério da Saúde. Portaria no 3088, de 23 de dezembro de 2011. Brasília: Ministério da Saúde, 2011.

BRASIL. Ministério da Saúde. Portaria GM no 130, de 26 de janeiro de 2012. Brasília: Ministério da Saúde, 2012.

BRASIL. Ministério da Saúde. Saúde Mental em Dados, n. 12, ano 10. Informativo eletrônico. Brasília: Ministério da Saúde, 2015. Disponível em: https:/www.mhinnovation.net/sites/ default/files/downloads/innovation/reports/Report_12-edicao-do-Saude-Mental-em-Dados. pdf. Acesso em: 8 abr 2019. 
BRASIL. Ministério da Saúde. Secretaria Executiva. Secretaria de Atenção à Saúde. Coordenação Nacional DST/AIDS. A política do Ministério da Saúde para a atenção integral a usuários de álcool e outras drogas. Brasília: Ministério da Saúde, 2003.

CAMPOS, G. W. de S. Clínica e Saúde Coletiva compartilhadas: Teoria Paidéia e Reformulação Ampliada do Trabalho em Saúde. In: CAMPOS, G. W. de S. et al. (Orgs.). Tratado de Saúde Coletiva. Rio de Janeiro: Hucitec-Fiocruz, 2006. p. 53-92.

CAMPOS, G. W. de S.; AMARAL, M. A. do. A clínica ampliada e compartilhada, a gestão democrática e redes de atenção como referenciais teórico-operacionais para a reforma do hospital. Ciênc. saúde coletiva, Rio de Janeiro, v. 12, n. 4, p. 849-859, ago. 2007.

CECILIO, L. C. de O. Apresentação. In: SOUZA, T. de P. Estado e sujeito: a saúde entre a macro e micro política de drogas. São Paulo: Hucitec, 2018. p. 13-22.

FODRA, R. E. P.; COSTA-ROSA, A. Centro de Atenção Psicossocial Álcool e Drogas: análise dos discursos e da prática no contexto da Reforma psiquiátrica e Atenção psicossocial. Revista Saúde em Debate, Rio de Janeiro, v. 33, n. 81, p.129-139, jan.-abr. 2009.

GOMES, R. et al. Organização, processamento, análise e interpretação de dados: o desafio da triangulação. In: MINAYO, M. C. S.; ASSIS, S. G.; SOUZA, E. R. (Orgs). Avaliação por triangulação de métodos. Rio de Janeiro: Fiocruz, 2005. p. 185-221.

LACERDA, C. de B.; FUENTES-ROJAS, M. Significados e sentidos atribuídos ao Centro de Atenção Psicossocial Álcool e outras Drogas (CAPS AD) por seus usuários: um estudo de caso. Interface (Botucatu), v. 21, n. 61, p. 363-372, Jun. 2017.

LOBOSQUE, A. M. Clinica em movimento: por uma sociedade sem manicômios. Rio de Janeiro: Garamond, 2003.

. Princípios para uma clínica antimanicomial. São Paulo: Hucitec, 1997.

MARQUES, A. L. M.; MANGIA, E. F. Itinerários terapêuticos de sujeitos com problemáticas decorrentes do uso prejudicial de álcool. Interface (Botucatu), v. 17, n. 45, p. 433-444, jun. 2013.

MINAYO, M. C. S. O desafio do conhecimento. 14a ed. São Paulo, Rio de Janeiro: HucitecAbrasco, 2014.

MORAES, M. O modelo de atenção integral à saúde para tratamento de problemas decorrentes do uso de álcool e outras drogas: percepçóes de usuários, acompanhantes e profissionais. Ciênc. saúde coletiva, Rio de Janeiro, v. 13, n. 1, p. 121-133, fev. 2008.

MOURA, F. G. de; SANTOS, J. E. dos. O cuidado aos usuários de um centro de atenção psicossocial álcool e drogas: uma visão do sujeito coletivo. SMAD, Rev. Eletrônica Saúde Mental Álcool Drog., Ribeirão Preto, v. 7, n. 3, p. 126-132, dez. 2011. 
ONOCKO-CAMPOS, R. T.; CAMPOS, G. W. de S. Co-construção de autonomia: o sujeito em questão In: CAMPOS, Gastão Wagner de Sousa et al. (Orgs). Tratado de Saúde Coletiva. Rio de Janeiro: Hucitec-Fiocruz, 2006. p. 669-689.

PARADA, C. O acolhimento revisitado. In: BAPTISTA, M.; CRUZ, M. S.; MATIAS, R. Drogas e pós-modernidade: prazer, sofrimento, tabu. Rio de Janeiro: Ed UERJ, 2003. p. 221-229.

SANTOS, B. de S. A sociologia das ausências e a sociologia das emergências: para uma ecologia dos saberes. In: SANTOS, B. de S. Renovar a teoria crítica e reinventar a emancipação social. São Paulo: Boitempo, 2007.

SILVA, R. A. da. Reforma psiquiátrica e redução de danos: um encontro intempestivo e decidido na construção política da clínica para sujeitos que se drogam. 2015. 199f. Dissertação (Mestrado em Promoção da Saúde e Prevenção da Violência) - Faculdade de Medicina. Universidade Federal de Minas Gerais, Belo Horizonte, 2015.

SOUZA, J. A doença da humilhação. In: . (Org.). Crack e exclusão social. Brasília: Ministério da Justiça e Cidadania, 2016. p. 29-37.

SOUZA, T. de P. Estado e sujeito: a saúde entre a macro e micro política de drogas. Sáo Paulo: Hucitec, 2018.

VASCONCELOS, M. P. N.; PAIVA, F. S. de; VECCHIA, M. D. O cuidado aos usuários de drogas: entre normatização e negação da autonomia. Gerais, Rev. Interinst. Psicol., Belo Horizonte, v. 11, n. 2, p. 363-381, 2018.

WANDEKOKEN, K.; QUINTANILHA, B.; DALBELLO-ARAUJO, M. Biopolítica na assistência aos usuários de álcool e outras drogas. Rev. Subj., Fortaleza, v. 15, n. 3, p. 389-397, dez. 2015.

\section{Nota}

${ }^{1}$ A. R. Machado participou da análise dos resultados, concepção e redação do artigo. C. M. Modena e Z. M. P. da Luz participaram da análise dos resultados, concepção e revisão crítica do artigo 


\section{Abstract}

From the policy propositions to the practices of the services: are there innovations in the Psychosocial Care Centers - Alcohol and Drugs? The Psychosocial Care Centers - Alcohol and Drugs (Caps AD) offer care in the Unified Health System for people with problems caused by drug use, based on innovations associated to the inclusion of psychosocial care and harm reduction in their conception of care. We carried out a qualitative research to understand how the practices of these services have been done, as well as the logic of the care they adopt, doing participant observation, semi structured interviews with managers, focal groups with users, family members and workers in three Caps AD in the city of Belo Horizonte-MG, Brazil. We noticed that these services prioritize practices that produce welcoming, bonds and attention to the health issues. They adopt harm reduction, psychosocial care and care as treatment logic. They perform this care with open services, but with little articulation with community and territorial resources. The research allowed us to understand that the Caps AD perform coherent practices with the proposed innovations, which seek to extend the life chances of people who use drugs.

Keywords: comprehensive health care; substance abuse treatment center; drug users. 